\title{
Comparison of magnesium versus titanium screw fixation for biplane chevron medial malleolar osteotomy in the treatment of osteochondral lesions of the talus
}

\author{
Metin Uzun ${ }^{1}$
}

Received: 22 January 2020 / Accepted: 18 March 2020 / Published online: 6 April 2020

○) Springer-Verlag France SAS, part of Springer Nature 2020

We were interested to read the article by Acar et al. published in European Journal of Orthopaedic Surgery \& Traumatology in 2020. The objective of the study was 'Comparison of magnesium versus titanium screw fixation for biplane chevron medial malleolar osteotomy in the treatment of osteochondral lesions of the talus' [1].

Honestly, the objective and results of the study are noteworthy and we have some questions for author:

1. Author said that splint was removed at 6 th week and then ROM exercise was started [1]. Total weight-bearing was encouraged at the end of 8-10 weeks. Total weightbearing was given following partial weight-bearing at the rehabilitation. Why didn't you start partial weightbearing?

2. Author pointed that, osteotomy union was achieved within the first 3 months, but CT images that follow-up the radiolucent zone using magnesium screws are given at Figure 6d, showing that not fully union at 4th month. Where does the difference in union times come from?

3. Author reported the rate of implant removal statistically similar in both groups. Author discussed the implant removal necessary lower compared to the other studies since headless screws and magnesium screws no needed the implant removal advantage. In this light, are we need to compare rate of implant removal rate? One patient

Metin Uzun

drmetinuzun@gmail.com

1 Acibadem Mehmet Ali Aydınlar University, Maslak Hospital, Darüşşafaka str, Büyükdere str No: 40, Maslak, Sariyer, Istanbul, Turkey screw was removed due to skin irritation. Is this a technical application error?

4. Author discussed that using magnesium screws would save more money due to lack of implant removal, but the implant removal rate was similar and union results were similar. Why should we use these expensive magnesium screws?

Funding This study was not funded.

\section{Compliance with ethical standards}

Conflict of interest The authors declare that they have no conflict of interest.

\section{Reference}

1. Acar B, Kose O, Unal M, Turan A, Kati YA, Guler F (2020) Comparison of magnesium versus titanium screw fixation for biplane chevron medial malleolar osteotomy in the treatment of osteochondral lesions of the talus. Eur J Orthop Surg Traumatol 30:163-173

Publisher's Note Springer Nature remains neutral with regard to jurisdictional claims in published maps and institutional affiliations. 